\title{
EXERCISE INTENSITY AND PERCEIVED EXERTION IN ADOLESCENT BOYS
}

\author{
R. G. ESTON, DPE and J. G. WILLIAMS, PhD
}

School of Physical Education and Recreation, University of Liverpool

\section{ABSTRACT}

The rating of perceived exertion (RPE) was assessed at power outputs (PO) corresponding to $30 \%, 60 \%$ and $90 \%$ of predicted maximal oxygen uptake $\left(\mathrm{VO}_{2}\right.$ max) on a cycle ergometer in 30 adolescent schoolboys (age range 15-17 years). Analysis of correlations $(r)$ for heart rate $(H R)$ : PO ( $r=0.74 p<0.01)$, RPE:PO $(r=0.78 p<0.01)$ and rating of perceived exertion (RPE): $\mathrm{HR}(r=0.74 p<0.01)$ were similar to values drawn from adult samples. It was concluded that there is a close relationship between RPE, HR and relative exercise intensity in adolescent schoolboys.

Key words: Exercise intensity, Perceived exertion, Adolescent males.

\section{INTRODUCTION}

The direct measurement of oxygen consumption and blood lactate concentration are good indicators of exercise intensity, but are hardly practical in a field setting. Thus, alternative methods of gauging exercise intensity have been devised. The linear relationship between heart rate and oxygen consumption is well established and is consequently used in a variety of tests and exercise protocols to gain an approximation of exercise intensity.

An important development in laboratory-based exercise science research of recent years is the strong trend towards the collection of information about how people feel whilst engaged in physical work to augment measures of physiological response. This stems from the realisation that physical performance results from a complex interaction of perceptual and cognitive activity as well as metabolic processes. One of the most common methods to quantify the extent of physical strain during exercise is the rating of perceived exertion (RPE), a fifteen-point category scale introduced by Borg (1970); Fig. 1. In general, the findings of fundamental research in the area of effort perception indicate that the exercise intensity judgements of adults correspond closely with concurrently gathered physiological indices such as heart rate, oxygen uptake, blood lactate accumulation, etc. (Pandolf, 1983; Carton and Rhodes, 1985). The implication is that a relatively simple, self report measure provided during exercise affords a direct link to fundamental information on the physiological state of the performing athlete which is normally only available in a laboratory setting.

$\begin{aligned} 6 & \\ 7 & \text { Very, very light } \\ 8 & \\ 9 & \text { Very light } \\ 10 & \\ 11 & \text { Fairly light } \\ 12 & \\ 13 & \text { Somewhat hard } \\ 14 & \\ 15 & \text { Hard } \\ 16 & \\ 17 & \text { Very hard } \\ 18 & \\ 19 & \text { Very, very hard } \\ 20 & \end{aligned}$

Fig. 1: The (RPE) scale for ratings of perceived exertion (Borg, 1970).

Research involving the perception of exertion has largely been based on the adult response. Several studies have reported high positive correlations between perceived exertion and oxygen uptake. Further, it would appear that a specific interval of RPE (e.g. 12-14) equates to $60-80$ per cent of maximal oxygen uptake in males and females in running and cycling tasks (Burke and Collins, 1984). However, there has been little research concerning the perceptual response to exercise in younger subjects. This information should be a positive input to the design of exercise programmes. A directly related index of effort perception should be a valuable, objective device when evaluating the training and competitive progress of young athletes.

The purpose of this investigation was to examine the relationship between perceived exertion (RPE), heart rate (HR), predicted maximum oxygen uptake ( $\mathrm{VO}_{2}$ max) and relative exercise intensity $\left(\% \mathrm{VO}_{2}\right.$ max) in adolescent males.

\section{METHODS}

Thirty healthy boys aged $15-17$ years drawn from four schools in the Merseyside area, volunteered as subjects for this study. Parental informed consent was given. No subject possessed any known pathological condition and all were physically active.

\section{Prediction of maximal power output}

A submaximal cycle ergometer test to predict maximal oxygen uptake and maximal power output was administered to each subject during a scheduled physical education lesson. The test was based on the established linear relationship between heart rate, work load and oxygen consumption, and consisted of work at three submaximal exercise levels designed to provide information on the relationship between heart rate and work load for each individual (Golding et al, 1982). This test is used widely by the YMCA and other institutions in the USA at present. Seat height on the ergometer was adjusted so that the ball of the subject's foot was resting on the pedal when the leg was fully extended.

Each subject cycled on a Tunturi-Puch cycle ergometer for $5 \mathrm{~min}$ at a power output of 50 watts at $60 \mathrm{rpm}$. Heart rate was measured each minute by pulse monitors PU10 and Exersentry (Respironics), which had previously been checked for interequipment reliability and validated against a Lifetrace 12 Cardiometer (Albury Instruments). Steady state was assumed if the difference in heart rate between the 3 rd and 4th min was not greater than 5 bts. $\mathrm{min}^{-1}$.

The work rate was then increased to a prescribed level (level 2) according to heart rate response, and maintained for 3 to 4 min until steady state was reached again. This procedure was repeated at a 3rd exercise level and the test terminated.

A line depicting the relationship between heart rate and power output was drawn between the steady state heart rate at level 2 and level 3 and interpolated to a maximal 
heart rate, based on the assumption (220-Age) bts. $\mathrm{min}^{-1}$. Maximal oxygen consumption and maximal power output were predicted from each individual relationship.

\section{Equating exercise intensity and acquisition of RPE}

On the second occasion, no later than 14 days after the first test was given, a further test was administered, this time designed to elicit $30 \%, 60 \%$ and $90 \%$ of each individual's predicted maximal power output. Pedalling rate and seat height were held constant and heart rate was measured with the same equipment. The order of each power output was randomised. Visual feedback from the various dials on the ergometer and the heart rate monitor was eliminated.

Subjects cycled for 3-4 min at each exercise level until a steady state heart rate was observed. During the last $15 \mathrm{sec}$ of each exercise level, the subject provided a numerical rating of effort intensity from the Borg 6-20 RPE scale (Borg, 1970). The instructions given prior to exercise were a suitably adapted version of those recommended by Bar-Or (1983). The exercise intensity was then altered to another level and the protocol repeated.

\section{RESULTS AND DISCUSSION}

The physical characteristics of the sample used in this study are summarised in Table I. Analysis of the relationships between HR, RPE and power output are summarised in Table II and represented graphically in Figs. 2, 3 and 4.

TABLE I

Physical characteristics and response to cycle ergometer test.

\begin{tabular}{|c|c|c|c|c|c|c|}
\hline & $\begin{array}{l}\text { Age } \\
\text { (yrs) }\end{array}$ & $\begin{array}{l}\text { Height } \\
\text { (cm) }\end{array}$ & $\begin{array}{c}\text { Woight } \\
\text { (kg) }\end{array}$ & $\begin{array}{c}\text { Predicted } \\
\text { Maximal } \\
\text { Power } \\
\text { Output } \\
\text { (W) }\end{array}$ & $\begin{array}{l}\text { Predicted } \\
\mathrm{VO}_{2} \max \\
{\text { I. } \min ^{-1}}^{-1}\end{array}$ & $\begin{array}{l}\text { Predicted } \\
\mathrm{VO}_{2} \text { max } \\
\text { mi.kg }\end{array}$ \\
\hline$\overline{\mathbf{x}}$ & 16.0 & 175.5 & 62.2 & 248.0 & 3.5 & 56.0 \\
\hline SD & \pm 1.0 & \pm 6.5 & \pm 10.8 & \pm 50.4 & \pm 0.7 & \pm 8.1 \\
\hline Range & $15-18$ & 164-186 & $42-89$ & $146-380$ & $2.5-6.0$ & $45-73$ \\
\hline
\end{tabular}

TABLE II

Correlation coefficient ( $r$ ) between heart rate (HR), rating of percelved exertion (RPE) and power output (PO) during an incremental cycle ergometer test $(n=30)$

\begin{tabular}{lcc}
\hline Relationship & r & p \\
\hline HR:Power output & 0.74 & $<0.01$ \\
RPE:HR & 0.74 & $<0.01$ \\
RPE:Power output & 0.78 & $<0.01$
\end{tabular}

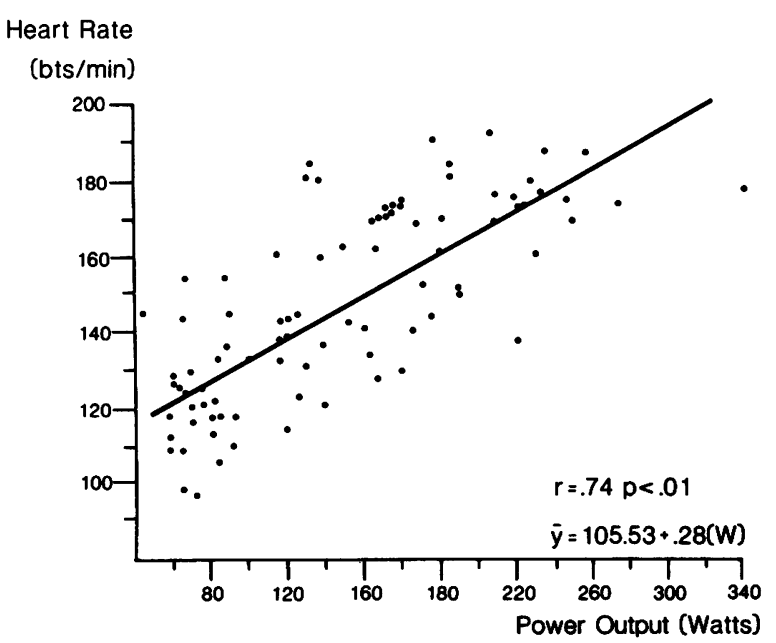

Fig. 2: Scattergram: Heart rate/power output $(n=90)$.

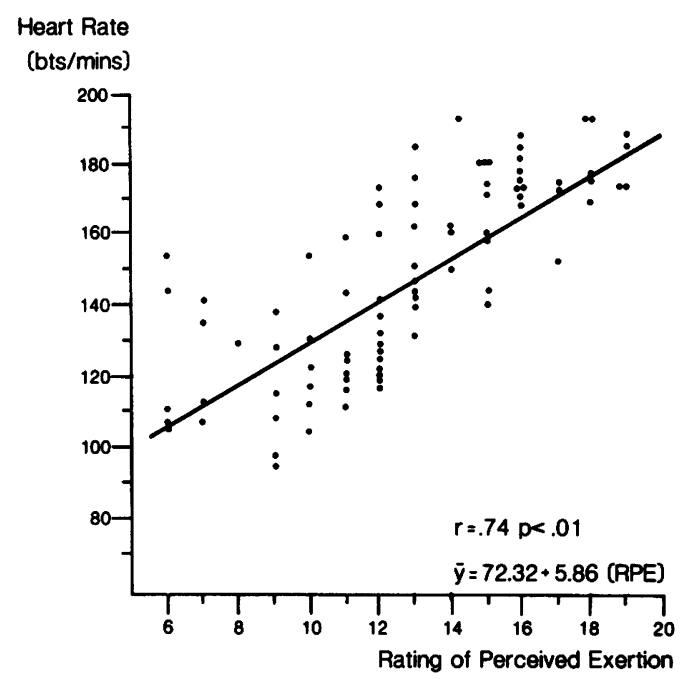

Fig. 3: Scattergram: Perceived exertion/heart rate $(n=90)$.

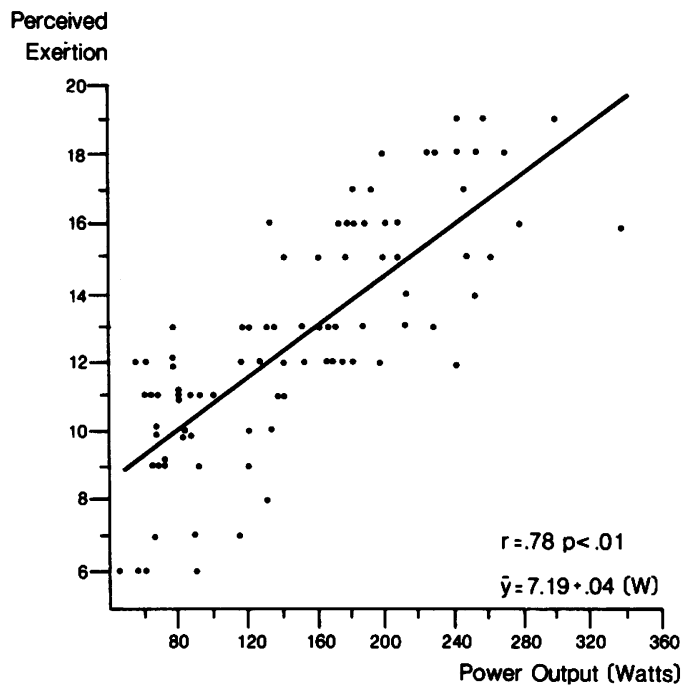

Fig. 4: Scattergram: Perceived exertion/power output $(n=90)$.

\section{Validity of the Predictive $\mathrm{VO}_{2}$ max test}

The test employed in this study was that currently recommended by the YMCA of the USA as the most convenient field method to assess cardiorespiratory endurance by cycle ergometry in adults. As the test was originally designed for an adult population, it was considered prudent to compare the reliability of the results with other studies and to assess the validity of the test with a practical field test of aerobic capacity which is easily employed in the school situation.

The predicted $\mathrm{VO}_{2} \max$ of $3.5 \mathrm{I} . \mathrm{min}^{-1}$ is consistent with normal values reported for a similar age group (Massicote et al, 1985). Similarly, the predicted relative $\mathrm{VO}_{2}$ max values in the present study appear to be in close agreement with measured relative $\mathrm{VO}_{2}$ max values reported in the literature. In a study involving the measurement of $\mathrm{VO}_{2} \max$ in 58 boys (age range 15-17 years), Massicote et al (1985) reported mean values of $56 \mathrm{ml} . \mathrm{kg}^{-1} \mathrm{~min}^{-1}$. Similarly, in a longitudinal study to assess the relationship between aerobic power, growth and training in boys, Kobayashi et al (1978) reported values of $54 \mathrm{ml}^{\mathrm{kg}}{ }^{-1} \mathrm{~min}^{-1}$ for $15-16$ year olds.

To gain further insight into the validity of the predictive $\mathrm{VO}_{2}$ max test for this age group, a random sub-sample of 8 boys were tested on the Cooper's 12-minute run. It has 
previously been suggested (Eston, 1984) that a prediction equation developed by Van der Walt and Wyndham (1973), based on running speed and body weight could conveniently be employed in schools to predict $\mathrm{VO}_{2} \max$ values in the 12-minute run.

Equation

$$
\begin{aligned}
& \mathrm{VO}_{2}= 0.419+0.03257(\mathrm{M})+0.000117\left(\mathrm{MV}^{2}\right) \\
& \text { where } \mathrm{M}=\text { mass in kilograms } \\
& \mathrm{V}=\text { speed in kilometres. } \mathrm{hr}^{-1}
\end{aligned}
$$

The literature supports the 12 minute run as a valid test of maximal oxygen uptake for the ages concerned in this study (Eston and Brodie, 1985).

Analysis of the relationship between the predicted $\mathrm{VO}_{2}$ max values (I. $\mathrm{min}^{-1}$ ) for cycle ergometry and the predicted $\mathrm{VO}_{2}$ max values $\left(1 . \mathrm{min}^{-1}\right)$ for the 12 minute run produced a high positive correlation $(r=0.92 p<0.01)$.

As a result of the above findings the investigators assumed that the cycle ergometer test described by Golding et al (1982) can be used to give reasonably accurate estimations of $\mathrm{VO}_{2}$ max for $15-17$ year olds, when this value is predicted from the 12 minute run performance. In the authors' opinion this test is the most convenient and practical field estimate which could be employed in healthrelated fitness curriculums in schools. The test therefore allowed an adequate assessment of three similar relative exercise intensities for all individuals so that RPE values could be compared.

Analysis of RPE, HR, Power Output and \% predicted $\mathrm{VO}_{2} \max$

The linear relationships between HR and power output (PO) $(r=0.74 p<0.01)$, RPE and PO $(r=0.78 p<0.01)$ and RPE and $H R(r=0.74 p<0.01)$ reported in previous studies was confirmed.

Following Borg's original report of a correlation of 0.85 between RPE and HR, numerous other studies have demonstrated the existence of a strong linear relationship between these two variables. This association has been noted for both male and female subjects (Skinner et al, 1973; Stamford, 1976), of varying fitness levels (Bar-Or et al, 1972; Skinner et al, 1973) while using either bicycle or treadmill exercise (Skinner et al, 1973), intermittent or continuous exercise (Edwards et al, 1972) and either arm or leg work (Eston and Brodie, 1986; Sargeant and Davies, 1973). Since maximal heart rate declines with age, it would be expected that RPE would be higher at a given heart rate in older subjects. This has been verified by reports in the literature (Arstila et al, 1977; Borg and Linderholm, 1967).

It has been suggested that RPE could be used as an estimate of exercise intensity (Burke and Collins, 1984). Indeed, Borg and Linderholm (1970) have demonstrated that the reproducibility of work capacity based upon an RPE at 13 and 17 is as good as that based upon a heart rate of 130 and 170 beats. min in both healthy subjects and cardiac patients. The close relationship of HR, RPE and \% $\mathrm{VO}_{2}$ max was also observed in the present study (Fig. 5). Studies involving adults have observed that an RPE ranging from 12-14 has equated in most individuals to $60-80 \% \mathrm{VO}_{2} \max$ (Burke and Collins, 1984; Eston and Burke, 1984; Sidney and Shephard, 1977 ) in running or cycling tasks. Similar RPE values were observed at $60 \% \mathrm{VO}_{2}$ max in the present study (Table III). This range corresponds with the recommended exercise intensity levels for the improvement of cardiovascular condition (American College of Sports medicine, 1978).

The mean rating of perceived exertion at $90 \%$ predicted $\mathrm{VO}_{2}$ max was similar to a recently reported study for 21 college-aged females in which $90 \% \mathrm{VO}_{2}$ max was measured directly (Eston and Burke, 1984).

\section{TABLE III}

\begin{tabular}{|c|c|c|c|}
\hline$\% \mathrm{VO}_{2} \max$ & $30 \%$ & $60 \%$ & $90 \%$ \\
\hline Heart Rate (bts. $\min ^{-1}$ ) & $120.5 \pm 14.3$ & $146.5 \pm 16.5$ & $173.2 \pm 10.8$ \\
\hline Perceived Exertion & $9.9 \pm 1.9$ & $12.2 \pm 2.3$ & $16.0 \pm 2.1$ \\
\hline
\end{tabular}

Mean heart rate and rating of perceived exertion at three exercise levels $\left(30 \%, 60 \%, 90 \% \mathrm{VO}_{2}\right.$ max)

Heart Rate

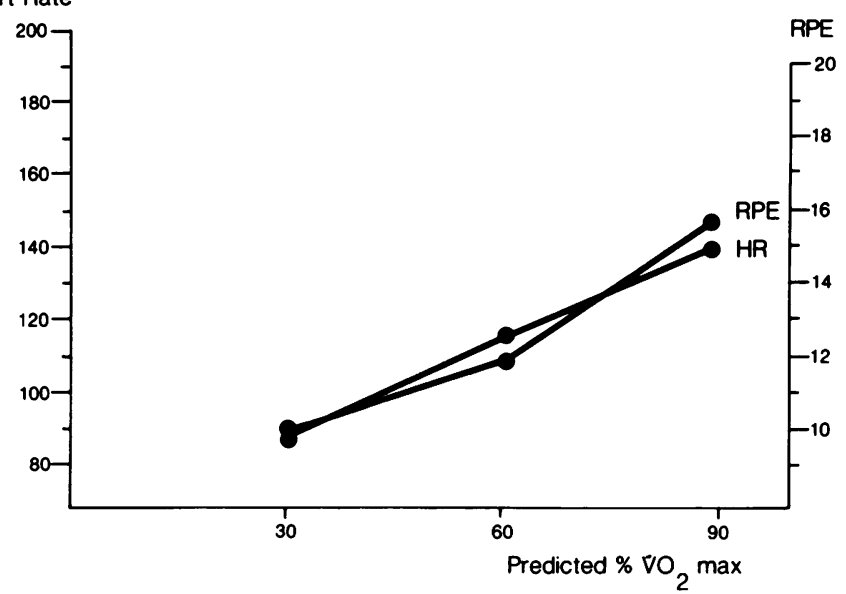

Fig. 5: Graph to show close relationship between heart rate/perceived exertion and proportion of $\mathrm{VO}_{2}$ max.

\section{CONCLUSION}

This study demonstrated the close relationship between perceived exertion, heart rate and exercise intensity in adolescent school boys. It demonstrates that boys in this age group perceive relative exercise intensity in a similar manner to adults. It is suggested that there are implications for the cardiovascular conditioning aspect of the school physical education curriculum and applications to sports coaching. It would appear that exercise intensity judgements of males in this group could be used to indicate suitable training intensities and it is suggested that these exercise perceptions may be learned to facilitate repetition of an adequate and personalised training stimulus. The use of perceived exertion to complement the assessment of exercise intensity is a positive diagnostic tool.

Although maximal oxygen uptake was not measured directly in this study, there is evidence to suggest that the YMCA submaximal cycle ergometer test is a good predictor of maximal oxygen uptake for this age group when this value is predicted from the 12 minute run. Furthermore, maximal oxygen uptake measurements cited in the literature agree closely with the values predicted from the YMCA cycle ergometer test used in this study. However, as maximal oxygen uptake was not measured directly, further study is needed to corroborate the validity of the predicted maximal oxygen uptake values based on the above methods.

\section{ACKNOWLEDGEMENTS}

This study was supported by a grant from the University of Liverpool Research Fund.

The authors thank the following physical education teachers for their co-operation in this study: Mr. M. Dooling, St. Augustine of Canterbury High School, Huyton; Mr. A. Rudge and Mr. P. Buckton, Fairfield High School, Widnes; Mr. J. Hennigan, De La Salle School, Liverpool; Mr. T. Askew, St. Mary's College, Crosby. 


\section{References}

American College of Sports Medicine, 1978 "Position statement on the recommended quantity and quality of exercise for developing and maintaining fitness in healthy adults". Med.Sci.Sports \& Exerc. 10: viii-x.

Arstila, M., Antilla, K., Wendelin, H., Vuori, I. and Valamaki, F., 1977 "The effect of age and sex on the perceptioin of effort during exercise test with a linear increase in heart rate". In Borg, G. (Ed.) Physical Work and Effort, pp. 217-221. (Solna, Pergamon Press, Sweden).

Bar-Or, O., 1983. Paediatric Sports Medicine for the Practitioner. (New York, Springer-Verlag).

Bar-Or, O., Skinner, J. S., Buskirk, E. R. and Borg, G., 1972 "Physiological and perceptual indicators of physical stress in 41 to 60 year-old men who vary in conditioning level and body fat". Med.Sci.in Sports 4: 96-10.

Borg, G., 1970 "Perceived exertion as an indicator of somatic stress". Scand.J.Rehab.Med. 2: 92-98.

Borg, G., and Linderholm, H., 1967 "Perceived exertion and pulse rate during graded exercise in various age groups". Acta Med.Scand. (Suppl. 472) 194-206.

Borg, G. and Linderholm, H., 1970 "Exercise performance and perceived exertion in patients with coronary insufficiency, arterial hypertension and vasoregulatory asthesia". Acta Med.Scand. 187: 7-26.

Burke, E. J. and Collins, M., 1984 "Using perceived exertion for the prescription of exercise in healthy adults". In Cantu, R.C. (Ed.) Clinical Sports Medicine (Lexington, Collamore Press, Massachusetts).

Carton, R. L. and Rhode, E. C., 1985 "A critical review of the literature on ratings scales for perceived exertion". Sports Med. 2: 198-222.

Edwards, R. H. T. Melcher, A., Hesser, C. M., Wigertz, O. and Ekelund, L. G. 1972 "Physiological correlates of perceived exertion in continuous and intermittent exercise with the same average power output". Eur.J.Clin. Invest. 2: 108-114.

Eston, R. G., 1984 "A discussion of the concepts: exercise intensity and perceived exertion with reference to the secondary school. Phys.Educ. Review 7 (1): 19-25.
Eston, R. G. and Brodie, D. A., 1985 "The assessment of maximal oxygen uptake from running tests". Phys.Educ. Review 8 (1): 26-34.

Eston, R. G. and Brodie, D. A., 1986 "Responses to arm and leg ergometry". Brit.J.Sports Med. 20: 4-6.

Eston, R. G. and Burke, E. J., 1984 "Effects of the menstrual cycle on selected responses to short constant-load exercise". J.Sports Scie 2: 145-153.

Golding, L. A., Myers,C. R. and Sinning, W. E. (Eds.), 1982. The Y's Way to Physical Fitness: A Guidebook for Instructors. Rosemont, Illinois, YMCA of the USA.

Kobayashi, K., Kitamura, K., Miura, M., Sodeyama, H., Murase, Y., Miyashita, $M$. and Matsui, H., 1978 "Aerobic power as related to body growth and training in Japanese boys: A longitudinal study". J.Appl.Physiol.: Respiratory, Environmental \& Exerc.Physiol. 44: 666-672.

Massicote, D. R., Gauthier, R. and Markon, P., 1985 "Prediction of $\mathrm{VO}_{2}$ max from the running performance in children aged 10-17 years". J.Sports Med.\& Phys. Fitness 25: 10-17.

Pandolf, K., 1983 "Advances in the study and application of perceived exertion". Exercise \& Sports Sci.Revs. 11: 118-158.

Sargeant, A. J. and Davies, C. T. M., 1973 "Perceived exertion during rhythmic exercise involving different muscle masses". J.Human Ergology 2: 3-11.

Sidney, K. H. and Shephard, R. J., 1977 "Perception of exertion in the elderly, effects of ageing, mode of exercise and physical training". Perceptual \& Motor Skills 44: 999-1010.

Skinner, J. S., Hustler, R., Bergsteinova, V. and Buskirk, E. R., 1973 "Perception of effort during different types of exercise and under different environmental conditions". Med.\& Sci. in Sports 5: 110-115.

Stamford, B. A., 1976 "Validity and reliability of subjective ratings of perceived exertion during work". Ergonomics 19: 53-60.

Van der Walt, W. H. and Wyndham, C. H., 1983 "An equation for prediction of energy expenditure of walking and running". Amer.J.Appl.Physiol. 34: 559-563. 